\title{
Nonlinear optics MathCAD exercise for undergraduate students
}

\section{Daniela Topasna, Gregory Topasna}

Daniela M. Topasna, Gregory A. Topasna, "Nonlinear optics MathCAD exercise for undergraduate students," Proc. SPIE 9665, Tenth International Topical Meeting on Education and Training in Optics and Photonics, 966523 (3 June 2007); doi: 10.1117/12.2211131

SPIE Event: Tenth International Topical Meeting on Education and Training in Optics and Photonics, 2007, Ottawa, Ontario, Canada 


\title{
Nonlinear Optics MathCAD Exercise for Undergraduate Students
}

\author{
Daniela M. Topasna and Gregory A. Topasna \\ Department of Physics and Astronomy \\ Virginia Military Institute, Lexington, VA 24450 \\ topasnadm@vmi.edu
}

\begin{abstract}
An educational experience in numerical modeling for physics majors at Virginia Military Institute has been created as part of the undergraduate research learning paradigm. As part of the independent project course required of all physics majors at VMI, those joining the thin films research group are taught the various stages of numerical modeling applied to complex problems (such as optical limiting) as a precursor to experimental work. Students are introduced to a realistic method of research involving open-ended experiments by this exercise. By teaching students how to design, create, and test a complex numerical model, they gain insight into how an experiment is set up and executed as well as what results can be anticipated. We present an exercise in which undergraduate students use MATHCAD in their modeling and calculations.
\end{abstract}

